\title{
Timing Assessment of Response to Fluid Challenge in Patients with Septic Shock
}

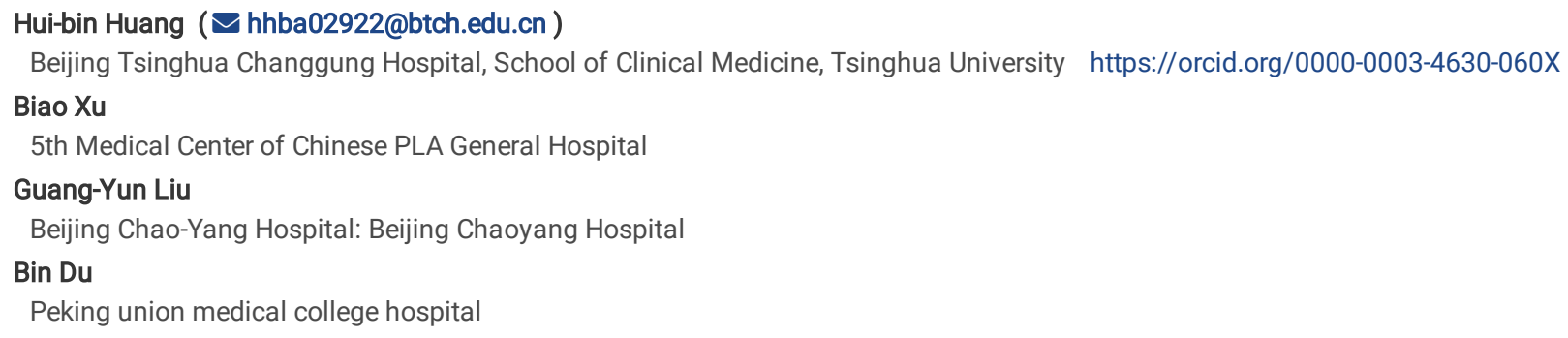

Research

Keywords: fluid challenge, fluid responsiveness, septic shock, assessment time, cardiac index.

Posted Date: November 10th, 2021

DOI: https://doi.org/10.21203/rs.3.rs-1042950/v1

License: (a) (i) This work is licensed under a Creative Commons Attribution 4.0 International License. Read Full License 


\section{Abstract}

Objectives: Fluid challenge (FC) is most commonly used for fluid responsiveness (FR) evaluation, with a wide divergence in assessment time choices. Therefore, we aimed to explore the optimal assessment time for FC in patients with septic shock.

Methods: A prospective cohort study was conducted. Septic shock patients who had experienced initial resuscitation and required an FC with 500 mL $4 \%$ gelatin or normal saline (NS) over 5-10 min were included. FR was defined by an increase in cardiac index $(\mathrm{Cl})>10 \%$. FR and other predefined variables were recorded at baseline $\left(T_{b}\right)$, immediately $\left(T_{0}\right)$, and at $10\left(T_{1}\right), 30\left(T_{2}\right), 45\left(T_{3}\right), 60\left(T_{4}\right), 90\left(T_{5}\right)$, and $120\left(T_{6}\right)$ min after FC. The incidence of FR and hemodynamic variables at predefined time points were recorded. Data were analyzed by repeated measures of analysis of variance.

Results: 63 patients were enrolled, with 43 in the gelatin group and 20 in the NS group. Among the 45/63 (71\%) responders, 31 were responded at $T_{0}$ (ER), while 14 responded at $T_{1}$ or later (LR). The proportion of NR, ER and LR was comparable between gelatin and NS groups. After FC, the time course of FR status was slightly different between gelatin and NS groups. In the gelatin group, FC induced most responders $(69 \%, 31 / 45)$ and frequency of Cl maximum $(35 \%, 11 / 31)$ at $\mathrm{T}_{2}$ and sustained a positive FR status until $\mathrm{T}_{4}$; while in the NS group, $\mathrm{FC}$ induced most responders $(55 \%, 11 / 20)$ and frequency of $\mathrm{Cl}$ maximum $(64 \%, 9 / 14)$ at $\mathrm{T}_{1}$, and sustained $\mathrm{FR}$ status until $\mathrm{T}_{1}$.

Conclusions: Different time courses of FR were found between gelatin and NS group patients undergoing FC. Thus, when NS is used, FR should be performed within $10 \mathrm{~min}$, while it is better to extend the assessment time to $30 \mathrm{~min}$ after $\mathrm{FC}$ when gelatin is used.

\section{Introduction}

Evaluation of fluid responsiveness (FR) is an essential maneuver in the management of fluid therapy in critically ill patients ${ }^{1}$. When FR was evaluated, only $40-50 \%$ of all these patients, including septic patients, responded ${ }^{2}$. On the other hand, fluid overload is harmful and associated with poor prognosis ${ }^{3-5}$. Therefore, some techniques for evaluating FR, such as fluid challenge (FC), are recommended to be first used when hypovolemia or preload dependency is suspected. ${ }^{6-8}$. FC refers to giving a certain amount of intravenous fluid quickly to assess the response of cardiac output (CO) to fluid infusion ${ }^{9}$. Although FC has been considered the gold standard for FR assessment, there is a wide divergence in performing it ${ }^{7,8}$. Among them, timing assessment of response to FC raises lots of concerns.

Most studies only reported a certain assessment time point of response to fluid infusion, ranging from the end of FC to 30 min thereafter 7,8 . However, hemodynamics after FC may change over time, while the persistence of FR after FC has been poorly described ${ }^{8,10}$. On the other hand, the degree and durations in intravascular distribution caused by different types of fluids (e.g., crystalloid or colloid) may also vary ${ }^{11,12}$. Additionally, some clinical factors such as blood volume status, cardiac function, and capillary leak severity of septic shock patients might further complicate the FC procedure ${ }^{13,14}$.

In some previous studies that focused on post-cardiac surgery patients receiving FC by $6 \%$ hydroxyethyl starch, nearly $74 \%$ (56-90\%) of included patients were deemed fluid responders when evaluated 10 min after $\mathrm{FC}^{15-19}$. This proportion was much higher than that in most other studies (54\%) assessing FR immediately after infusion ${ }^{8}$. Therefore, we could speculate that some patients who had shown immediate negative response at the end of infusion might become responders at 10 min after FC. In the FCREV study ${ }^{20}$, Roger and colleagues also observed this phenomenon; among the 67 non-responders at the end of FC, 4 became responders 20 min later. Moreover, Aya et al. enrolled 26 postoperative patients in their FC study (250 ml crystalloid infusion over 5 min) and found the effect of fluid infusion dissipated in $10 \mathrm{~min}$ in these patients ${ }^{21}$. However, a recent meta-analysis focusing on FC showed $13 \%$ (11/85) of the included studies evaluated FR at a time point of $\geq 10 \mathrm{~min}$ after the fluid bolus ${ }^{8}$. As such, the proportion of responders may be different when evaluating FR at different assessment time points.

Therefore, we sought to perform a prospective cohort study to determine the optimal assessment time after FC in patients with septic shock. Additionally, we further compared the effect of different fluids on FR, such as gelatin or normal saline (NS), by investigating the hemodynamics for 120 min after FC. We hypothesized that optimal assessment time might be different when using different types of fluids.

\section{Methods}

\section{Study protocol}

This prospective observational study was approved by the Ethical Committee of Peking Union Medical College Hospital and was registered at ClinicalTrial.gov (NCT01941472). Written informed consent was obtained from all patients or their relatives. We performed this study in our 15-bed medical intensive care unit (ICU) between September 2015 and November 2018. A flowchart of the study design is shown in Additional file 1.

\section{Patients}

All adult patients were eligible if they were diagnosed with septic shock according to international criteria ${ }^{22}$ and required an FC during their stay in ICU. We excluded patients known with severe cardiac dysfunction (i.e., acute pulmonary edema, acute coronary syndrome,and cardiogenic shock), pregnancy, and participation in other biomedical studies, requiring blood transfusion or imminent death within 24 hours. Also, we excluded patients who required aggressive fluid therapy (fluid infused $>200 \mathrm{~mL} / \mathrm{h}$ ), dose changes in sedatives, inotropic or vasoactive agents, or adjustments to ventilator parameters during the study period.

\section{Hemodynamic monitoring}


We monitored arterial blood pressure from an arterial line (Becton Dickinson infusion therapy systems Linc., Utah, USA) placed in a radial artery or dorsalis pedis artery; and measured CVP with a central venous catheter (CV-15854; Arrow International, Reading, PA) inserted into the internal jugular vein in all patients. CVP and blood pressure were measured with a transducer zeroed at the level of the midaxillary line of the thorax. The $\mathrm{Cl}$ was calculated by the continuous thermodilution technique equipped with a PAC (Swan-Ganz CCOmbo CCO/SvO , Edwards Lifesciences, Irvine, CA, USA). We connected all the above catheters to pressure transducers and the IntelliVue Patient Monitor MP70 (Philips Medical System, Boeblingen, Germany).

\section{Fluid challenge}

According to our protocol, reasons for FC included hypotension (SBP $\leq 90 \mathrm{mmHg}$ or SBP decrease $\geq 40$ mmHg in patients with hypertension or MAP $\leq 65$ $\mathrm{mmHg}$ ), presence of tissue hypoperfusion (including, but not limited to, oliguria, skin mottling, cool peripheries, altered mental status, hyperlactatemia, and increased requirement for catecholamine). For the FC administration, $500 \mathrm{ml}$ of $4 \%$ gelatin (Gelofusine; B. Braun Medical (Suzhou) Company Limited, Suzhou, China) or NS were intravenous infusions over 5-10 min using a bag pressurized to $300 \mathrm{mmHg}$. Positive $\mathrm{FR}$ was defined as an increase in $\mathrm{Cl}>10 \%$ after $\mathrm{FC}^{9}$. The fluid infused, starting and termination of FC were decided by clinicians. The patients were followed during FC and for 120 min after FC. During the observational period, the maintenance infusions were limited to a maximum of $100 \mathrm{~mL} / \mathrm{h}$, without any changes made to agents, ventilatory settings, and other therapeutic interventions.

\section{Parameters and outcomes}

Once enrolled in our study, demographics, fluid types, Acute Physiology and Chronic Health Evaluation II score, underlying diseases, and clinical data concerning therapies (mechanical ventilation, renal replacement therapy, sedatives, catecholamine used) were collected for included patients. We recorded a complete set of hemodynamic and oxygen metabolism variables for analysis at baseline $\left(T_{b}\right)$, immediately $\left(T_{0}\right)$, and at $10\left(T_{1}\right), 30\left(T_{2}\right), 45\left(T_{3}\right), 60\left(T_{4}\right), 90$ $\left(\mathrm{T}_{5}\right)$ and $120\left(\mathrm{~T}_{6}\right)$ min after $\mathrm{FC}$. Hemodynamic variables included mean arterial pressure (MAP), heart rate (HR), Cl, CVP, pulmonary arterial wedge pressure (PAWP), systemic vascular resistance index (SVRI). In contrast, oxygen metabolism indexes included $\mathrm{SaO}_{2}, \mathrm{PaO}_{2}, \mathrm{PH}$, mixed venous oxygen saturation $\left(\mathrm{SvO}_{2}\right)$, hemoglobin $(\mathrm{Hb})$, and arterial lactate concentrations obtained from blood sample analysis at every predefined study point.

The primary outcome was the positive response rate to $\mathrm{FC}$ at different time points during the study period. The secondary outcomes were the time course of hemodynamic variables before and after FC. We also explored the effect of fluid type (gelatin and NS) on the FR In this scenario.

\section{Statistical analysis}

Categorical variables were expressed as numbers (\%), whereas continuous variables were expressed by the means \pm standard deviation (SD) or by the medians along with 25-75\% interquartile ranges (IQR), as appropriate. Before FC, patient characteristics between gelatin and NS groups were compared using Student's $T$ or Mann-Whitney U for continuous data and the chi-square test or Fisher's exact tests for categorical data, according to their distribution. After FC, a two-way repeated measure analysis of variance was used to compare the hemodynamic and metabolism variables among the patients grouped by fluid types or FR status at all the predefined time points. MedCalc statistical software version 15.6.1 for Windows and GraphPad Prism 7 were used in the present study. A 2-sided $P$ value less than 0.05 was considered statistically significant.

\section{Result}

\section{Patient characteristics}

Sixty-three patients were finally recruited (Additional file 2), with 43 patients in the gelatin group and 20 in the NS group. Patient baseline characteristics and clinical data were comparable between the groups (Table 1). All patients had a mean age of 63 years with a mean APACHE II score of 25 at enrolment. Hypotension was the most common cause of FC, following by increased catecholamine requirement and hyperlactatemia. Twenty-nine patients died during their ICU stay. 
Table 1

Patient characteristics before fluid challenge

\begin{tabular}{|c|c|c|c|c|}
\hline Variables & Total $(n=63)$ & Gelatin $(n=43)$ & Normal saline $(n=20)$ & $P$ \\
\hline Age, year & $63(53-72)$ & $61(49-71)$ & $66(55-74)$ & 0.319 \\
\hline Male, $\mathrm{n}$ & 41 & 28 & 13 & 0.889 \\
\hline Body surface area $\left(\mathrm{m}^{2}\right)$ & $1.8(1.7-1.9)$ & $1.8(1.7-1.9)$ & $1.8(1.8-2.0)$ & 0.717 \\
\hline APACHE II & $25(21-30)$ & $26(21-31)$ & $23.5(20.5-29.5)$ & 0.684 \\
\hline \multicolumn{5}{|l|}{ Cause of FC, $n$} \\
\hline Hyperlactatemia & 22 & 15 & 7 & 0.783 \\
\hline Oliguria & 19 & 13 & 6 & 0.782 \\
\hline Hypotension & 43 & 29 & 14 & 0.928 \\
\hline Tachycardia & 19 & 17 & 7 & 0.947 \\
\hline Skin mottling & 8 & 5 & 2 & 0.811 \\
\hline Reduce vasopressors & 24 & 16 & 7 & 0.911 \\
\hline Others & 1 & 1 & 0 & 0.693 \\
\hline $\mathrm{PaO}_{2} / \mathrm{FiO}_{2}$ & $165(111-244)$ & $159(107-237)$ & $196(130-247)$ & 0.229 \\
\hline Ventilated patient, $\mathrm{n}$ & 59 & 40 & 19 & 0.798 \\
\hline CRRT, n & 11 & 9 & 2 & 0.479 \\
\hline \multicolumn{5}{|l|}{ Ventilated mode } \\
\hline $\mathrm{PC} / \mathrm{VC}$ & 38 & 27 & 11 & 0.668 \\
\hline PS & 21 & 13 & 8 & 0.632 \\
\hline PEEP, mmHg & $6(4-10)$ & $8(4.5-12)$ & $5(4-9.5)$ & 0.218 \\
\hline \multicolumn{5}{|l|}{ Type of vasopressor } \\
\hline $\mathrm{NE}, \mathrm{n}$ & 62 & 42 & 20 & 0.712 \\
\hline $\mathrm{NE}, \mu \mathrm{g} / \mathrm{kg} / \mathrm{min}$ & $0.5(0.3-1.1)$ & $0.6(0.4-1.1)$ & $0.3(0.3-1.2)$ & 0.337 \\
\hline $\mathrm{EPI}, \mathrm{n}$ & 4 & 2 & 2 & 0.598 \\
\hline $\mathrm{EPI}, \mu \mathrm{g} / \mathrm{kg} / \mathrm{min}$ & 0.19 & 0.24 & 0.14 & 0.672 \\
\hline Fluid balance, L & $2.1(1.6-2.6)$ & $2.0(1.7-2.3)$ & $1.9(1.5-2.1)$ & 0.451 \\
\hline Fluid maintenance, $\mathrm{mL}$ & $100(71-100)$ & $100(63.8-120)$ & $100(75-100)$ & 0.444 \\
\hline ICU mortality, n & 29 & 19 & 10 & 0.873 \\
\hline \multicolumn{5}{|c|}{ Data are expressed in median (interquartile range) or mean \pm SD or count. } \\
\hline
\end{tabular}

\section{Fluid responsiveness assessment}

Forty-five patients were responders,with 31 in the gelatin group and 14 in the NS group. As to the 18 persistent non-responders (NR), 12 were in the gelatin group and 6 in the NS group. Among the responders, 31 responded immediately at $T_{0}$, while 14 became responders at or after $T_{1}$. Thus, we defined these patients as early responders (ER) and later responders (LR), respectively. The baseline clinical data of NR, ER, and LR are summarized in Additional file 3.

After FC, the FR status distribution at the predefined time points was slightly different between the gelatin and NS groups. In the gelatin group, the positive response to FC was most commonly seen at $T_{2}(69 \%, 31 / 45)$, following by $T_{1}(66 \%, 30 / 45)$ and $T_{3}(62 \%, 28 / 45)$, while in the NS group, FC induced the most responders at $T_{1}(55 \%, 11 / 20)$, following by $T_{2}(45 \%, 9 / 20)$ and $T_{0}(45 \%, 9 / 20)$ (Fig. 1: A). Similarly, the Cl maximum $\left(\mathrm{Cl}_{\text {max }}\right)$ distribution at each time point is also different between groups. That is, the time point at which $\mathrm{Cl}_{\max }$ appeared most frequently was at $\mathrm{T}_{2}(35 \%, 11 / 31)$ in the gelatin group, while at $\mathrm{T}_{1}(64 \%$, 9/14) in the NS group (Fig. 1: B).

\section{Hemodynamic assessment}


Hemodynamic variables at each predefined time point were summarized according to fluid types (gelatin and NS), or FR status (NR, ER, and LR) are shown in Additional file 4 and Table 2, respectively. Overall, $\mathrm{Cl}$ increased significantly in both gelatin and NS groups at $\mathrm{T}_{0}$, with different trends over time. In the gelatin group, $\mathrm{Cl}$ increased to a maximum at $\mathrm{T}_{2}$ and maintained an increase in $\mathrm{Cl}>10 \%$ before $\mathrm{T}_{4}$. In the $\mathrm{NS}$ group, $\mathrm{Cl}$ increased to a maximum at $\mathrm{T}_{1}$ and decreased to baseline at $\mathrm{T}_{3}$ (Fig. 2A). Subsequently, we further explored $\mathrm{Cl}$ changes over time in NR, ER, and LR subgroup patients. In the gelatin group, ER and LR became responders at $T_{0}$ and $T_{1}$, respectively, and then achieved $\mathrm{Cl}_{\max }$ at $\mathrm{T}_{2}$ and maintained positive $F R$ until $T_{6}$ (Fig. $2 B$ ). As to the NS group, ER and $L R$ responded at $T_{0}$ and $T_{1}$, respectively, and then presented $\mathrm{Cl}_{\max }$ at $T_{1}$. Finally, ER and $L R$ changed their $F R$ status from $R$ to $N R$ at $T_{3}$ and $T_{2}$. $C l$ did not significantly increase over time in NR of both groups after FC (Fig. 2C). The time courses of other hemodynamic variables before and after FC are shown in Additional file 5 .

Table 2

Comparison of patient characteristics of hemodynamics at predefined time points among non-responders, early responders, and late responders

\begin{tabular}{|c|c|c|c|c|c|c|c|c|c|}
\hline Variables & & $T_{b}$ & $\mathrm{~T}_{0}$ & $\mathrm{~T}_{1}$ & $\mathrm{~T}_{2}$ & $\mathrm{~T}_{3}$ & $\mathrm{~T}_{4}$ & $\mathrm{~T}_{5}$ & $T_{6}$ \\
\hline \multirow{3}{*}{$\begin{array}{l}\text { MAP } \\
(\mathrm{mmHg})\end{array}$} & ER & $81.7 \pm 11.1$ & $88.8 \pm 14.4$ & $87.3 \pm 15.6$ & $86.2 \pm 11.0$ & $83.6 \pm 11.1$ & $84.1 \pm 11.3$ & $83.5 \pm 12.3$ & $81.5 \pm 9.4$ \\
\hline & LR & $82.3 \pm 7.6$ & $89.2 \pm 14.0$ & $88.4 \pm 16.2$ & $89.6 \pm 15.6$ & $86.6 \pm 15.1$ & $87.8 \pm 13.2$ & $87.5 \pm 13.9$ & $84.5 \pm 12.6$ \\
\hline & NR & $83.3 \pm 13.3$ & $85.9 \pm 11.7$ & $85.7 \pm 12.1$ & $83.4 \pm 9.8$ & $83.3 \pm 10.6$ & $84.1 \pm 11.5$ & $83.7 \pm 11.9$ & $82.4 \pm 12.9$ \\
\hline \multirow{3}{*}{$\begin{array}{l}\mathrm{HR} \\
(\mathrm{bpm})\end{array}$} & ER & $117.3 \pm 23.7$ & $113.4 \pm 21.9$ & $113.9 \pm 21.8$ & $116.3 \pm 23.3$ & $115.5 \pm 24.1$ & $116.5 \pm 23.4$ & $116.4 \pm 22.8$ & $117.0 \pm 22.8$ \\
\hline & LR & $107.3 \pm 18.3$ & $105.9 \pm 13.9$ & $105.4 \pm 12.9$ & $107 \pm 15.8$ & $105.9 \pm 14.2$ & $106.9 \pm 13.6$ & $107.7 \pm 16.5$ & $108.7 \pm 17.7$ \\
\hline & $N R$ & $116.1 \pm 19.3$ & $112.0 \pm 18.4$ & $112.2 \pm 19.8$ & $115.5 \pm 18.7$ & $115.6 \pm 18.4$ & $115.8 \pm 17.9$ & $117.0 \pm 18.9$ & $117.2 \pm 18.7$ \\
\hline \multirow{3}{*}{$\begin{array}{l}\mathrm{Hb} \\
(\mathrm{g} / \mathrm{L})\end{array}$} & ER & $100.1 \pm 27.7$ & $90.5 \pm 24.1$ & $91.1 \pm 23.7$ & $91.3 \pm 24.4$ & $91.9 \pm 24.4$ & $91.9 \pm 24.5$ & $93.3 \pm 24.7$ & $93.6 \pm 25.4$ \\
\hline & LR & $91.6 \pm 27.1$ & $81.6 \pm 25.7$ & $82.6 \pm 24.7$ & $84.2 \pm 24.8$ & $84.3 \pm 24.7$ & $84.9 \pm 24.6$ & $84.6 \pm 24.4$ & $85.1 \pm 25.3$ \\
\hline & NR & $82.8 \pm 15.9$ & $77.6 \pm 19.2$ & $76.6 \pm 17.6$ & $76.6 \pm 17.2$ & $78.8 \pm 16.9$ & $78.4 \pm 17.5$ & $79.7 \pm 17.0$ & $76.9 \pm 18.0$ \\
\hline \multirow{3}{*}{$\begin{array}{l}\text { CVP } \\
(\mathrm{mmHg})\end{array}$} & ER & $9.9 \pm 4.5$ & $12.7 \pm 4.7$ & $12.1 \pm 4.3$ & $11.4 \pm 4.3$ & $11.1 \pm 4.3$ & $10.9 \pm 4.4$ & $10.7 \pm 4.3$ & $10.2 \pm 4.2$ \\
\hline & LR & $11.8 \pm 3.1$ & $14.5 \pm 3.3$ & $13.8 \pm 3.2$ & $13.1 \pm 2.9$ & $12.6 \pm 2.6$ & $12.6 \pm 3.0$ & $12.1 \pm 2.7$ & $11.9 \pm 2.8$ \\
\hline & NR & $11.5 \pm 5.0$ & $15.9 \pm 5.7$ & $14.7 \pm 5.9$ & $13.8 \pm 5.8$ & $13.7 \pm 5.9$ & $13.4 \pm 5.9$ & $13.1 \pm 5.9$ & $12.8 \pm 5.6$ \\
\hline \multirow[t]{3}{*}{$\mathrm{Cl}$} & ER & $3.5 \pm 1.0$ & $4.1 \pm 1.1$ & $4.5 \pm 1.3$ & $4.4 \pm 1.3$ & $4.4 \pm 1.3$ & $4.1 \pm 1.1$ & $4.0 \pm 1.1$ & $3.9 \pm 1.1$ \\
\hline & LR & $3.8 \pm 1.7$ & $4.0 \pm 1.6$ & $4.5 \pm 2.0$ & $4.5 \pm 1.7$ & $4.5 \pm 1.7$ & $4.3 \pm 1.6$ & $4.2 \pm 1.5$ & $4.3 \pm 1.6$ \\
\hline & NR & $4.2 \pm 1.1$ & $4.1 \pm 1.1$ & $4.2 \pm 1.1$ & $4.2 \pm 1.3$ & $4.2 \pm 1.2$ & $4.1 \pm 1.1$ & $4.1 \pm 1.0$ & $4.0 \pm 1.2$ \\
\hline \multirow[t]{3}{*}{ SVRI } & ER & $1839.4 \pm 691.3$ & $1625.5 \pm 817.6$ & $1494.4 \pm 703.6$ & $1474.3 \pm 571.3$ & $1438.2 \pm 545.4$ & $1539.1 \pm 644.7$ & $1557.7 \pm 616$ & $1542.2 \pm 552.9$ \\
\hline & LR & $1533.5 \pm 574.6$ & $1699.8 \pm 790.3$ & $1545.8 \pm 735.1$ & $1507.9 \pm 622.0$ & $1468.3 \pm 643.8$ & $1540.6 \pm 764.1$ & $1634.2 \pm 865.6$ & $1537.7 \pm 869.7$ \\
\hline & NR & $1445.6 \pm 452.1$ & $1430.9 \pm 418.5$ & $1406.1 \pm 376.7$ & $1407.8 \pm 427.8$ & $1397.3 \pm 420.1$ & $1454.4 \pm 470.0$ & $1437.8 \pm 416.2$ & $1477.4 \pm 870.0$ \\
\hline \multicolumn{10}{|c|}{$\begin{array}{l}\mathrm{Cl}=\text { cardiac output index; } \mathrm{CVP}=\text { central venous } \mathrm{pr} \\
\mathrm{MAP}=\text { mean arterial pressure; NS = normal saline; }\end{array}$} \\
\hline \multicolumn{10}{|c|}{$\mathrm{T}_{0}=$ immediately at end of FC (fluid challenge); } \\
\hline \multicolumn{10}{|c|}{$\mathrm{T}_{1}=10 \mathrm{~min}$ after $\mathrm{FC}$} \\
\hline \multicolumn{10}{|c|}{$\mathrm{T}_{2}=30 \mathrm{~min}$ after $\mathrm{FC}$} \\
\hline \multicolumn{10}{|c|}{$\mathrm{T}_{3}=45 \mathrm{~min}$ after $\mathrm{FC}$} \\
\hline \multicolumn{10}{|c|}{$\mathrm{T}_{4}=60 \mathrm{~min}$ after $\mathrm{FC}$} \\
\hline \multicolumn{10}{|c|}{$\mathrm{T}_{5}=90 \mathrm{~min}$ after $\mathrm{FC}$} \\
\hline
\end{tabular}

\section{Discussion}

The main findings of our study are, first, the proportion of NR, ER, and LR were comparable between gelatin and NS groups; second, FC induced the most frequency of $\mathrm{Cl}_{\max }$ at $\mathrm{T}_{2}$ and $\mathrm{T}_{1}$ in gelatin and NS groups, respectively, and the positive FR status sustained until $\mathrm{T}_{4}$ in gelatin group, while until $\mathrm{T}_{1}$ in $\mathrm{NS}$ group; third, 14 patients identified as $\mathrm{NR}$ at $\mathrm{T}_{0}$ became $\mathrm{LR}$ at $\mathrm{T}_{1}$ or later, and both $\mathrm{ER}$ and $\mathrm{LR}$ achieved $\mathrm{Cl}_{\max }$ at $\mathrm{T}_{2}$ after $\mathrm{FC}$ in gelatin group, whereas at $\mathrm{T}_{1}$ in NS group. 
Our results showed gelatin exhibited a longer duration of positive response status than NS after FC. This might be due to the difference in hemodynamic effects between crystalloid and colloid. That is, colloid can maintain a longer-term hemodynamic effect when compared with crystalloid in equal scenario $^{11,23}$. In a recent randomized trial, Gondos and colleagues examined the kinetics of volume loading with crystalloid and colloid infusions in 200 critically ill patients, and they found that $6 \%$ hydroxyethyl starch still produced a change in $\mathrm{Cl}(23 \%)$ at 120 min after infusion, while this effect dissipated in lactated Ringer's solution ${ }^{11}$.

On the other hand, positive response status over time to FC may also be affected by patient populations and details in performing FC (i.e., a CO monitoring technique, duration or volume of infusion $)^{20,21}$. In their pharmacodynamic analysis in FC (250 ml crystalloid, injected in 5 min), Aya et al. found the maximal $\mathrm{CO}$ increase was observed $1 \mathrm{~min}$ after the end of FC, and the fluid bolus effect disappeared in $10 \mathrm{~min}^{21}$. However, in the FCREV study (500 ml crystalloid infusion, $10 \mathrm{~min}), 30 \%(43 / 143)$ patients exhibited positive responses to infusion 20 min after $\mathrm{FC}^{20}$.

Interestingly, 22\% (14/63) of patients showed an initial negative response immediately after FC subsequently converted to LR. We called these patients "late responders to FC." Such a phenomenon was observed in septic shock patients ${ }^{20}$ or post-cardiac surgery patients ${ }^{15-19}$ in some previously published studies. These patients are likely to be overlooked when FR is only evaluated immediately at the end of the infusion. Thus, this finding supports our hypothesis that timing assessment of FR could affect the proportion of patients responding to FC. However, our conclusion is in contrast with a recently published metaanalysis that focused on $\mathrm{FC}^{8}$. In this study, the authors grouped the 86 included studies into three categories based on assessment time (immediately, between 1 and $10 \mathrm{~min}$, or >10 min after FC) and found FR timing assessment did not affect the proportion of responders. Of note, the pooled results of types of fluids (crystalloid or colloid), FR criteria (10\% or 15\%), techniques (PICCO, PAC, or ultrasound), and setting (ICU and operating room) might contribute to the significant heterogeneity among the included studies, Thus leading to their negative results ${ }^{8}$.

Another important finding is the different distribution of $\mathrm{Cl}_{\max }$ between gelatin and $\mathrm{NS}$ after $\mathrm{FC}$ may provide meaningful clues to aid in the timing of assessment. When NS is used, FR should be performed from the end of FC to 10 min that after. Conversely, if the FR assessment was performed too later, some patients might have already changed their FR status from R to NR at that time point. Thus, these patients are susceptible to be identified as NR. In a randomized trial comparing hemodynamics in septic shock patients who received either hypotonic or hypertonic fluid ${ }^{24}$, the authors found only $30 \%$ ( $3 / 12$ ) and $33 \%(4 / 12)$ responders in the two groups at 30 min after FC. Similarly, Nunes and colleagues identified all the responders at the end of FC. This may because they evaluated FR at the end of $\mathrm{FC}$ and 30 min thereafter ${ }^{10}$. As to gelatin, it is better to extend the assessment time to 30 min after $\mathrm{FC}$, especially for patients who show negative responses immediately after infusion. Of note, the $\mathrm{Cl}$ course over time was significantly different among LR, ER, and NR $(P<0.001)$ as well as baseline $\mathrm{Cl}\left(4.6 \pm 1.0,3.5 \pm 1.0,3.1 \pm 1.0 \mathrm{~L} / \mathrm{min} / \mathrm{m}^{2}\right.$, respectively). Thus, we assume that $\mathrm{Cl}$ values at baseline might help identify $\mathrm{NR}$, and LR fluid responders immediately at the end of infusion and further research is warranted in the future.

The current study explored the effects of crystalloid and colloid on the time course of FR in septic shock and suggested reasonable ranges of FR assessment time. However, some details in our study design worth discussion. First, we used gelatin and NS in our study. Reasons for this included that NS is the most commonly used crystalloid ${ }^{7}$, safety considerations of hydroxyethyl starch $^{25}$, and the availability of gelatin in our unit. However, it should be cautious about extrapolating our conclusion to other types of fluids since previous studies have demonstrated that various fluids (i.e., lactated Ringer's solution, gelatin,hydroxyethyl starch, or album) exhibited different hemodynamic effects over time after volume loading ${ }^{11}$. Second, the volume of fluid used was 500 $\mathrm{ml}$, the current "mainstream volume" selection for $\mathrm{FC}^{26}$. However, whether our results could also be applied for other fixed fluid volumes (i.e., $250 \mathrm{ml}$ ) or fluid volume adjusted for body-weight remains unclear. This would require further investigation. Third, the process of FC was completed in about 6 min, which is faster than most other FC studies 8,10 . Theoretically, the shorter infusion duration, the larger proportion volume of fluid will remain in the intravascular compartment at the end of infusion, and a higher positive FR rate may be obtained. This was also confirmed by the meta-analysis result, which demonstrated that the proportion response to an FC given in $\geq 30$ min was lower than that in $<15 \min (P=0.045)^{8}$. Thus, this might indirectly add evidence for the reliability of negative FR in LR patients immediately after FC in the current study. Finally, we explored the time course of FR in 120 min after fluid infusion, a relatively longer period compared to the previous studies ${ }^{10,20,21}$. Apart from the purpose of a complete recording of hemodynamic effects on $\mathrm{FR}$, the main consideration for this is the tolerability of volume-limited (infusion $<100 \mathrm{~mL} / \mathrm{h}$ ) during $120 \mathrm{~min}$ in the enrolled patients. Overall, no adverse events were observed during the study period, which may be related to the initial fluid resuscitation performed in these patients before enrollment.

Our study had several limitations. The first and main limitation is the incapability to fully explain our results from the pathophysiology mechanism due to the pure observation nature of the current study, especially for LR patients. Nevertheless, our data may, at the very least, encourage clinicians to reevaluate their practice in deciding timing assessment of response to FC in septic shock patients. Second, FR was evaluated at only 7 predefined time points referred to most previous studies $8,10,11,27$. However, our results suggest that more assessment time points may be essential in the early stage after FC, especially in crystalloid group patients with relatively short periods of hemodynamic effect. Finally, only septic shock patients having received initial fluid resuscitation were included according to the current protocol. However, the fully initial fluid resuscitation has not been strictly defined and lacked individuation. A previous study reported FC ( $5 \mathrm{ml} / \mathrm{kg}$ crystalloid solution infusion over $15 \mathrm{~min}$ ) induced a significant increase in $\mathrm{CO}$ and sustained for 120 min in severe hypovolemic sepsis patients without initial fluid resuscitation. Whether our results could apply to such a patient population is unclear.

\section{Conclusion}

Significant differences were found in time courses of hemodynamic effects in septic shock patients receiving $500 \mathrm{ml}$ gelatin or NS for FC. Therefore, the timing assessment of response to FR differs between the two types of fluids. When NS is used, FR should be performed from the end of FC to 10 min that after, while it is better to extend assessment time to $30 \mathrm{~min}$ after FC in gelatin, especially for patients who show negative responses immediately after infusion. 


\section{Declarations}

\section{Author contributions:}

Dr. Huang contributed to the data collection, analysis, and drafting of the article. Dr. Liu and Dr. Xu contributed to data collection, literature search, and writing of the manuscript. Dr. Du was responsible for the work integrity as a whole, from inception to publication of the article.

\section{Acknowledgements $\square$}

Not applicable.

\section{Availability of data and materials $\square$}

All data generated or analyzed during this study are included in this published article.

\section{Financial/nonfinancial disclosures:}

The authors have reported that no potential conflicts of interest exist with any companies/organizations whose products or services may be discussed in this article.

\section{Role of funding source:}

There was no funding source for this study.

\section{Ethics approval and consent to participate]}

Not applicable.

\section{Consent for publication}

Not applicable.

\section{Competing interests[}

The authors declare that they have no competing interests.

\section{Trial registration:}

ClinicalTrials.gov, NCT 01941472. Registered 13 September 2013, available at https://clinicaltrials.gov/ct2/show/NCT01941472

\section{References}

1. Rhodes A, Evans LE, Alhazzani W, et al. Surviving Sepsis Campaign: International Guidelines for Management of Sepsis and Septic Shock: 2016. Critical care medicine. 2017;43(3):486-552.

2. F M, JL T. Predicting fluid responsiveness in ICU patients: a critical analysis of the evidence. Chest. 2002;121(6):2000-2008.

3. Alsous F, Khamiees M, DeGirolamo A, Amoateng-Adjepong Y, Manthous CA. Negative fluid balance predicts survival in patients with septic shock: a retrospective pilot study. Chest. 2000;117(6):1749-1754.

4. Payen D, de Pont AC, Sakr Y, Spies C, Reinhart K, Vincent JL. A positive fluid balance is associated with a worse outcome in patients with acute renal failure. Critical care (London, England). 2008;12(3):R74.

5. Boyd JH, Forbes J, Nakada TA, Walley KR, Russell JA. Fluid resuscitation in septic shock: a positive fluid balance and elevated central venous pressure are associated with increased mortality. Critical care medicine. 2011;39(2):259-265.

6. Ueyama H, Kiyonaka S. Predicting the Need for Fluid Therapy-Does Fluid Responsiveness Work? Journal of intensive care. $2017 ; 5: 34$.

7. Messina A, Longhini F, Coppo C, et al. Use of the Fluid Challenge in Critically III Adult Patients: A Systematic Review. Anesthesia and analgesia. 2017;125(5):1532-1543.

8. Toscani L, Aya HD, Antonakaki D, et al. What is the impact of the fluid challenge technique on diagnosis of fluid responsiveness? A systematic review and meta-analysis. Critical care (London, England). 2017;21(1):207.

9. Marik PE, Monnet X, Teboul JL. Hemodynamic parameters to guide fluid therapy. Transfusion Alternatives in Transfusion Medicine. 2011;1(3):1-1.

10. Nunes TS, Ladeira RT, Bafi AT, de Azevedo LC, Machado FR, Freitas FG. Duration of hemodynamic effects of crystalloids in patients with circulatory shock after initial resuscitation. Ann Intensive Care. 2014;4:25

11. Gondos T, Marjanek Z, Ulakcsai Z, et al. Short-term effectiveness of different volume replacement therapies in postoperative hypovolaemic patients. Eur J Anaesthesiol. 2010;27(9):794-800. 
12. Verheij J, van Lingen A, Beishuizen A, et al. Cardiac response is greater for colloid than saline fluid loading after cardiac or vascular surgery. Intensive Care Med. 2006;32(7):1030-1038.

13. Fleck A, Raines G, Hawker F, et al. Increased vascular permeability: a major cause of hypoalbuminaemia in disease and injury. Lancet. 1985;1(8432):781-784.

14. Trof RJ, Sukul SP, Twisk JW, Girbes AR, Groeneveld AB. Greater cardiac response of colloid than saline fluid loading in septic and non-septic critically ill patients with clinical hypovolaemia. Intensive Care Med. 2010;36(4):697-701.

15. Fellahi JL, Fischer MO, Dalbera A, Massetti M, Gerard JL, Hanouz JL. Can endotracheal bioimpedance cardiography assess hemodynamic response to passive leg raising following cardiac surgery? Ann Intensive Care. 2012;2(1):26.

16. Fellahi JL, Fischer MO, Rebet $\mathrm{O}$, et al. Cerebral and somatic near-infrared spectroscopy measurements during fluid challenge in cardiac surgery patients: a descriptive pilot study. Journal of cardiothoracic and vascular anesthesia. 2013;27(2):266-272.

17. Fischer MO, Coucoravas J, Truong J, et al. Assessment of changes in cardiac index and fluid responsiveness: a comparison of Nexfin and transpulmonary thermodilution. Acta anaesthesiologica Scandinavica. 2013;57(6):704-712.

18. Fischer MO, Pelissier A, Bohadana D, Gerard JL, Hanouz JL, Fellahi JL. Prediction of responsiveness to an intravenous fluid challenge in patients after cardiac surgery with cardiopulmonary bypass: a comparison between arterial pulse pressure variation and digital plethysmographic variability index. Journal of cardiothoracic and vascular anesthesia. 2013;27(6):1087-1093.

19. Fischer MO, Pellissier A, Saplacan V, Gerard JL, Hanouz JL, Fellahi JL. Cephalic versus digital plethysmographic variability index measurement: a comparative pilot study in cardiac surgery patients. Journal of cardiothoracic and vascular anesthesia. 2014;28(6):1510-1515.

20. Roger C, Zieleskiewicz L, Demattei C, et al. Time course of fluid responsiveness in sepsis: the fluid challenge revisiting (FCREV) study. Critical care (London, England). 2019;23(1):179.

21. Aya HD, Ster IC, Fletcher N, Grounds RM, Rhodes A, Cecconi M. Pharmacodynamic Analysis of a Fluid Challenge. Critical care medicine. 2016;44(5):880891.

22. Dellinger RP, Levy MM, Rhodes A, et al. Surviving Sepsis Campaign: international guidelines for management of severe sepsis and septic shock, 2012. Intensive Care Med. 2013;39(2):165-228.

23. Verheij J, van Lingen A, Raijmakers PG, et al. Effect of fluid loading with saline or colloids on pulmonary permeability, oedema and lung injury score after cardiac and major vascular surgery. British journal of anaesthesia. 2006;96(1):21-30.

24. van Haren FM, Sleigh J, Boerma EC, et al. Hypertonic fluid administration in patients with septic shock: a prospective randomized controlled pilot study. Shock. 2012;37(3):268-275.

25. Dart AB, Mutter TC, Ruth CA, Taback SP. Hydroxyethyl starch (HES) versus other fluid therapies: effects on kidney function. The Cochrane database of systematic reviews. 2010(1):Cd007594.

26. Cecconi M, Hofer C, Teboul JL, et al. Fluid challenges in intensive care: the FENICE study: A global inception cohort study. Intensive Care Med. 2015;41(9):1529-1537.

27. Rothe CF. Reflex control of veins and vascular capacitance. Physiological reviews. 1983;63(4):1281-1342.

\section{Figures}



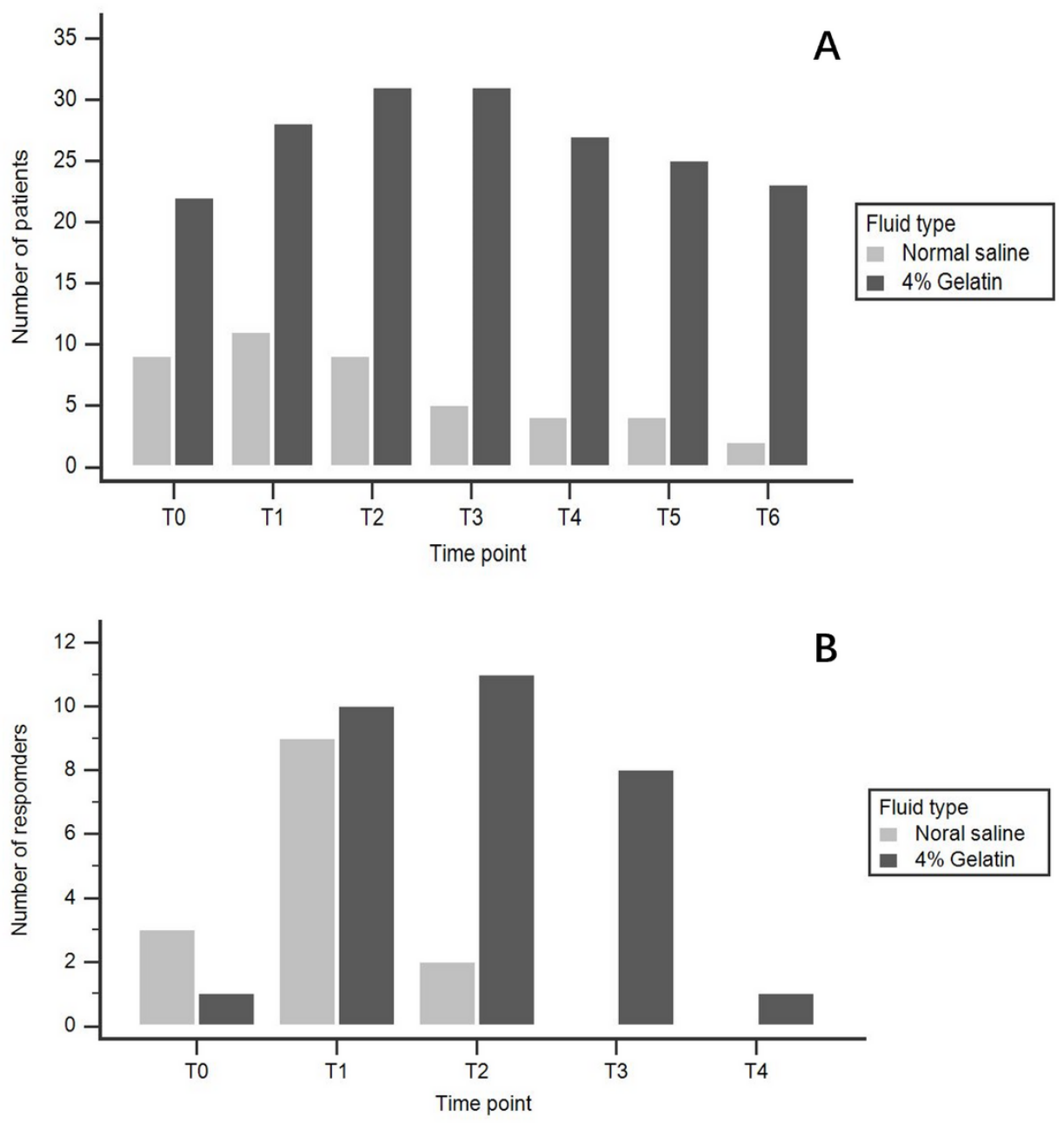

Figure 1

(A) Distribution of responders at the predefined time points in two groups; (B) Distribution of $\mathrm{Cl}$ max at the predefined time points in responders. 



Figure 2

(A) $\mathrm{Cl}$ changes over time in normal saline and gelatin groups; (B) $\mathrm{Cl}$ changes over time in subgroups of early responders, late responders and non-responders receiving gelatin; $(\mathrm{C}) \mathrm{Cl}$ changes over time in subgroups of early responders, late responders and non-responders receiving normal saline.

\section{Supplementary Files}

This is a list of supplementary files associated with this preprint. Click to download.

- Additionalfile15.docx 